\title{
LOS DERECHOS HUMANOS COMO PRINCIPIOS DE ORDEN PÚBLICO INTERNACIONAL EN EL DERECHO INTERNACIONAL PRIVADO ARGENTINO Y DEL MERCOSUR.
}

\section{THE HUMANS RIGHTS AS PRINCIPLES OF INTERNATIONAL PUBLIC ORDER IN THE PRIVATE INTERNATIONAL LAW OF ARGENTINA AND OF MERCOSUR}

\author{
Milton C. Feuillade \\ miltonfeuillade@hotmail.com
}

Recebido em: 23-1-2016

Aprovado em: 23-1-2016

Sumario: I.- Introducción. II.- Primacía de los Tratados u orden de prelación de las normas en la Argentina. III.- Los Tratados de Integración en la Constitución.IV.- Sistema de aprobación y jerarquía constitucional de los Tratados del Mercosur.V.- Cuestión de competencia entre la nación y las provincias.VI.- El Orden Público Internacional Argentino. VII.- El Orden Público Internacional en el Mercosur. VIII.- Conclusiones.

\section{Resumen:}

La República Argentina se enrola desde su normativa y jurisprudencia en un monismo acentuado que es la tendencia mundial ante la globalización y la internacionalización dándose como se dijo primacía al derecho internacional por sobre el derecho interno. Los Tratados de Derechos Humanos y las sentencias de la CorteIDH desde la incorporación al texto constitucional y el control de convencionalidad forman parte del acervo de Orden Público Internacional de la República Argentina y de los Estados del Mercosur, pero en cuento conjunto de principios aplicados a posteriori no se reduce solamente a ello o al memos los

\section{Abstract:}

Argentina Republic is emerged since its legislation and jurisprudence in a marked monism which is the global trend to globalization and internationalization giving, as it is said, the primacy to the international law over domestic law. The Treaties on Human Rights and the rulings of the InterAmerican Court of Human Rights since the incorporation into the Constitution and the conventionality control are part of the heritage of International Public Order of Argentina Republic and the MERCOSUR states, but as far a group of principles applied "a posteriori" it doesn't exclusively reduce to it at least not in the States which are not 
Estados en la medida que no contraríen a la CorteIDH, no se reduce a solamente a ello.

Palabras Clave:

Orden Público Internacional. Derecho Internacional Privado Argentino. Mercosur. Derechos Humanos. Corte Interamericana de Derechos Humanos. contrary to the Inter-American Court of Humans Rights,

\section{Key-words:}

Public International Order. Private International Law of Argentina. MERCOSUR. Inter-American Court of Human Rights.

\section{Introducción.}

En este trabajo analizaremos un aspecto que a nuestro criterio es esencial en la aplicación del Derecho Extranjero, en el reconocimiento de una sentencia extranjera así como en la cooperación jurisdiccional internacional y por lo tanto toca a la resolución práctica del caso de Derecho Internacional Privado.

Se verá en especial la incidencia de los Derechos Humanos en el contenido del Orden Público Internacional. Por razones de extensión se hará en general, pero deseamos dejar aclarado que el enfoque es hacia todos los Derechos Humanos, con lo cual, por ejemplo el derecho a la propiedad en el constante tráfico externo, desde la orientación a un mercado común que pretende el Mercosur.

A su vez, la orientación desde una perspectiva de brindar derecho comparado es el Derecho Argentino, desde el funcionamiento, aprobación y jerarquía de los tratados en su diferentes tipos a la concretización del Orden Público Internacional como conjunto de principios.

Para otra oportunidad de dejará el abordaje de las normas de policía y de aplicación inmediata.

Otro tema que, por cuestiones de extensión no se desarrollará, pero se dará por asumido es el Control de Convencionalidad respecto de la jurisprudencia de la CorteIDH.

\section{Primacía de los Tratados u orden de prelación de las normas en la Argentina.}

Respecto del orden de prelación de la normas se parte del art. 31 de la C.N. en cuanto a la declaración de los Tratados como ley suprema de la nación ${ }^{1}$, cabe aquí realizar la

\footnotetext{
1 Reza el art. 31 de la C.N.: "Esta Constitución, las leyes de la Nación que en su consecuencia se dicten por el Congreso y los tratados con las potencias extranjeras son la ley suprema de la Nación; y las autoridades de cada provincia están obligadas a conformarse a ellas, no obstante cualquiera disposición en contrario que contengan las leyes o constituciones provinciales, salvo para la provincia de Buenos Aires, los tratados ratificados después del Pacto de 11 de noviembre de 1859".
} 
calificación del término Tratados diciendo que abarca todos los acuerdos, pactos, convenios concordatos y convenciones internacionales, escritos o no escritos ${ }^{2}$. A su vez tenemos el art. 27 que establece que todo Tratado debe estar de conformidad con la C.N. ${ }^{3}$; esto se conjuga con la Convención de Viena de 1969 sobre derecho de los Tratados ${ }^{4}$, cuyo art. 27 establece que: "Una parte no podrá invocar las disposiciones de su derecho interno como justificación del incumplimiento de un tratado". Norma que en su segunda parte posee una excepción cuando dice que: "Esta norma se entenderá sin perjuicio de lo dispuesto en el artículo 46". Dicho art. 46 refiere a la nulidad de los Tratados diciendo: "El hecho de que el consentimiento de un Estado en obligarse por un tratado haya sido manifiesto en violación de una disposición de su derecho interno concerniente a la competencia para celebrar tratados no podrá ser alegado por dicho Estado como vicio de su consentimiento, a menos que esa violación sea manifiesta y afecte a una norma de importancia fundamental de su derecho interno".

Creemos que al incorporarse la Convención de Viena, el Tratado alcanza eficacia aunque no se adecue a la Constitución. Si Argentina se negase a cumplir un Tratado estaría atentando contra los principios de buena fe y de cumplimiento de los Tratados en el "pacta suntservanda", incurriendo en la respectiva responsabilidad internacional por este incumplimiento 5 .

Ya lo ha dicho el ius filósofo Ciuro Caldani ${ }^{6}$ que atenta contra la justicia el negar el consentimiento prestado en los Tratados. Luego también cabe traer a colación el art. 75 inc. 22 de la C.N. cuando establece que: "Los Tratados y Concordatos tienen jerarquía superior a las leyes".

En definitiva de todo lo expuesto se concluye que no se puede invocar la legislación del Estado, incluso la Constitución, excepto en las circunstancias expuestas en el art. 46 para incumplir un Tratado.

Toda esta normativa deja a la República enrolada en un monismo acentuado que es la tendencia mundial, ante la globalización y la internacionalización, dándose como se dijo primacía al derecho internacional por sobre el derecho interno ${ }^{7}$.

\footnotetext{
2 Sagüés, Néstor Pedro; "Elementos de Derecho Constitucional"; ed. Astrea; 2da. ed.; Buenos Aires 1997; Tomo 1; 574 págs.; pág. 219.

$3 \quad$ Establece el art. 27 de la C.N.: "El Gobierno federal está obligado a afianzar sus relaciones de paz y comercio con las potencias extranjeras por medio de tratados que estén en conformidad con los principios de derecho público establecidos en esta Constitución".

$4 \quad$ Que para la república es ley no 19865.

5 Sagüés, Néstor Pedro; "Elementos de DerechoConst..."; op. cit.; pág. 220.

$6 \quad$ CiuroCaldani, Miguel Ángel; "Comprensión lusfilosófica de las Características de los Tratados Internacionales y el Consentimiento en la Comunidad internacional"; Rev. A.A.D.I.; No XIV; Córdoba, 2005; págs. 17 a 31 ; pág. 25.

7 Vanossi, Jorge Reinaldo A. - Dalla Via, Alberto Ricardo; "Régimen Constitucional de los Tratados"; ed. Abeledo - Perrot; Buenos Aires, 2000; 2 da. ed.; 470 págs.; pág. 288.
} 
Coincidimos con Sagüés ${ }^{8}$ cuando habla de la tesis de la diferenciación normativa en cuanto ley y Tratados son normas de naturaleza jurídica distinta, siendo la ley una expresión unilateral del Estado y el Tratado, aunque se apruebe por cada país, es una norma de naturaleza compleja, producto de la voluntad de al menos dos Estados. Concluye el mencionado autor diciendo que un Tratado no puede modificarse por una ley, porque se afectarían los principios internacionales del iuscogens, de buena fe y de "pacta suntservanda", por lo que el Tratado sólo es alterable por otro Tratado.

A su vez tenemos los Tratados incorporados constitucionalmente del art. 75 inc. 22 referentes a Derechos Humanos, que están conforme al texto constitucional en el mismo plano de la C.N., en las condiciones de su vigencia y sin derogar parte alguna de las declaraciones derechos y garantías consagrados en la C.N..

Haciendo un breve recorrido jurisprudencial, cabe traer a colación el caso "Fibraca Constructora S.C.A. v. Comisión Técnica Mixta de Salto Grande" ${ }^{10}$ donde se determinó que existiendo un tribunal arbitral que resolviera las controversias generadas respecto de la mencionada organización internacional, debía considerarse la inmunidad de jurisdicción inserta en su estatuto, toda vez que no se produjo denegación de justicia en virtud del cumplimiento de la Convención de Viena de derecho de los Tratados, reconociéndose por tanto la subordinación de la legislación interna a los Tratados, quedando derogadas las leyes persistentes que los contradigan y no pudiendo el Congreso dictar leyes en su contra ${ }^{11}$.

En cuanto a la naturaleza de los Tratados debe destacarse la jurisprudencia del caso "Méndez Valles, Fernando c/ A.M. Pescio S.C.A. s/ejecución de alquileres"12, donde se establece la naturaleza federal, habiéndose dicho en su oportunidad en el considerando $9^{\circ}$

\footnotetext{
8 Sagüés, Néstor Pedro; "Elementos de DerechoConst..."; op. cit.; pág. 225.

$9 \quad$ Otros autores como Barboza, Julio; "Derecho Internacional Público"; ed. Zavalía; Buenos Aires, 2001; 750 págs.; pág. 79, se enrolan en otra postura diciendo que los Tratados del 75 inc 22: "Tienen jerarquía supralegal, pero infraconstitucional, porque están sujetos a los principios de derecho público de la Constitución según el art. 27 de la C.N.. Esto permite concluir que pueden ser declarados inconstitucionales, generando la correspondiente responsabilidad internacional del Estado Argentino, pero no pueden ser declarados ilegales". En la misma línea encontramos a: Vanossi, Jorge Reinaldo A. - Dalla Via, Alberto Ricardo; "Régimen Constitucional..."; op. cit.; pág. 322; al decir: "Los Tratados internacionales de derechos humanos con jerarquía constitucional están en el piso superior de la pirámide jurídica pero no exactamente en el vértice porque, como indica el mismo inciso, están un escalón debajo del texto constitucional al no poder derogar ningún artículo de la primera parte y tener carácter complementario, que significa "accesorio", y no principal como la Constitución Nacional. Tal interpretación es también la que mejor se concilia con la supremacia Constitucional en cuanto reserva la última decisión en materia internacional."
}

10

Dado por la CSJN el 7 de julio de 1993; J.A.; Tomo 1993 - IV; págs. 472 y ss.; con nota de Cueto Rúa, Julio C.; "Un Paso Adelante en el Desarrollo de la Justicia Arbitral en la Argentina". Y: Caivano, Roque J.; "El Arbitraje y los Procesos de Integración"; J.A.; Tomo 1996 - II; págs. 783 a 795.

$11 \quad$ Caivano, Roque J.; "La Supremacía de los Tratados y el Arbitraje Internacional en la Jurisprudencia de la Corte"; J.A.; Tomo 1998 - I; págs. 565 a 568. Este artículo es comentario del caso "Ghiorzo, Juan J. c. Comisión Técnica Mixta Salto Grande", donde se decidió la inmunidad de jurisdicción de la organización internacional y la competencia de ela para decidir por arbitraje las cuestiones que le fueren planteadas.

12 Dado por la CSJN, el 26 de diciembre de 1995; L.L.; Tomo 1996-C; págs. 501 y ss.; con nota de Bidart Campos, Germán; "La naturaleza federal de los Tratados Internacionales". 
que: "El Tratado internacional es una norma orgánicamente federal, que importa un acto federal complejo...", dándose un vuelco con la anterior jurisprudencia, que distinguía cuándo las normas de un Tratado funcionan como preceptos de derecho común que no daba lugar a la cuestión federal, y cuándo funcionaban como normas del derecho internacional diciendo en el considerando $10^{\circ}$ que: “...La naturaleza federal del Tratado alcanza también a su contenido. Es irrelevante que la materia del Tratado sea de las calificadas como derecho común, aun cuando se incorporen las normas del Tratado a una ley nacional común. Nada de ello puede enervar la sustancia federal que aquéllas poseen en virtud de su fuente internacional"13.

La jurisprudencia argentina puede clasificarse en distintos períodos, el primero fue un criterio dualista rígido, con la necesidad del dictado de una ley para convertir el derecho internacional en derecho interno teniendo como paradigma el caso "Merck Química"14; este criterio fue flexibilizado en el caso "Yerbatera Martin S.A." 15 , al calificar a las leyes y los Tratados igualmente como ley suprema de la nación, pero sin dar prioridad de rango a ninguno. En el año 1992 el caso "Ekmekjián"16 se reconoce la primacía del derecho internacional sobre el derecho interno, casualmente a partir del derecho a réplica contenido en el Pacto de San José de Costa Rica, que no estaba reglamentado internamente, pero se consideró al Tratado autoejecutable sin reglamentación, volcándose por un monismo atenuado, criterio que se ratifica con contundencia en el caso "La Virginia", para culminar con el reciente fallo "Simón" ${ }^{17}$,donde la Corte a nuestro criterio se vuelca por un monismo extremo.

La consecuencia de todo esto es que la Argentina, dentro de todo su marco convencional, no podrá dictar leyes internas que contraríen un Tratado y si así lo establecieran devendrían inaplicables.

\section{Los Tratados de Integración en la Constitución.}

En cuanto a los Tratados de integración tenemos el inc. 24 del art. $75^{18}$ de la C.N., en que se entiende que el constituyente ha apoyado los procesos de integración, asignando a dichos Tratados jerarquía superior a las leyes y habilitando la modificación de competencias de los poderes

\footnotetext{
$13 \quad$ En la misma línea a pesar de haber sido denegado el recurso, se orienta la interpretación realizada por la disidencia del Ministro Boggiano en el caso: "París Video Home v. Societá per AzioniComercialelniziativeSpettacolo"; J.A.; Tomo 1996 - III; págs. 18 y ss..

$14 \quad$ Fallos: $211: 162$

$15 \quad$ Fallos: 257: 99.

16 L.L.; Tomo 1992 - C; págs. 543 y ss.

17 S. 1767. XXXVIII. "Simón, Julio Héctor y otros s/ privación ilegítima de la libertad, etc. - causa Nº 17.768-; CSJN ; 14/06/2005. En Internet: www.csjn.gov.ar ; 13/07/06.

18 Dice el inciso: "Aprobar tratados de integración que deleguen competencias y jurisdicción a organizaciones supraestatales en condiciones de reciprocidad e igualdad, y que respeten el orden democrático y los derechos humanos. Las normas dictadas en su consecuencia tienen jerarquía superior a las leyes...."
} 
del Estado Argentino, a favor de un ente regional, siendo las condiciones que se observen los principios de igualdad y reciprocidad, el respeto al orden democrático y a los derechos humanos, que deben ser aprobados por la mayoría absoluta de los miembros de cada Cámara.

Su inclusión, dentro de esa parte de la Constitución, ha sido criticada, aunque su motivo es que no podía conforme a la ley 24.309, sobre la necesidad de la reforma de la Constitución de incluirse dentro de las Declaraciones Derecho y Garantías, porque hubiese implicado su prohibida reforma, pero: "El art. 31 de la Constitución Nacional está encuadrado dentro de la parte de declaraciones, derechos y garantías y estaría siendo interpretado por un artículo de la parte de la autoridades de la Nación'"19.

El inc. 24 abre la posibilidad a una triple delegación de competencias, que implica el ceder el ejercicio soberano de ciertas atribuciones y que mira al Derecho Comunitario Europeo, pensándose en un máximo estadio de integración dado por un Mercado Común o una Unión Económica y Monetaria. El segundo aspecto es la delegación jurisdiccional orientada a un Tribunal de Justicia Común, tal como lo es el T.J.C.E. y un tercer aspecto es la delegación a organismos supraestatales, permitiendo a futuro la supremacía del derecho derivado de los Tratados de Integración sobre las leyes domésticas ${ }^{20}$.

A continuación como salvaguarda se establecen las condiciones de "reciprocidad" para ceder las mencionadas competencias, que a interpretación de Natale supone que los países miembros deben ceder similares competencias a los organismos ${ }^{21}$.

Ligado a la mencionada reciprocidad se establecen las condiciones de igualdad, que, a decir de la doctrina ${ }^{22}$, tiene un doble aspecto: económico y jurídico. Así es que pueden reconocerse asimetrías en las economías de los países, dato ineludible de la realidad, situación que se compensa con cláusulas de salvaguardia en los Tratados. Desde el punto de vista jurídico, la asimetría puede provenir de la distinta jerarquía legal a la normativa emanada de los órganos comunes. De todas formas, la igualdad no obsta un sistema de votos ponderados, siempre que se reflejen la proporcionalidad de los derechos y las obligaciones de las partes.

Como tercer requisito tendremos el respeto al orden democrático. Democracia e integración son conceptos íntimamente ligados, sin que pueda concebirse un proceso integrador fuera de este marco. En este sentido cabe traer a colación los instrumentos firmados sobre la materia entre los que se encuentran la: "Declaración Presidencial Sobre Compromiso Democrático en el Mercosur"; del 25 de junio de 1996, de San Luis,

\footnotetext{
$12 \quad$ Peña, Julián; "Los Tratados de la Integración en el Nuevo Orden Constitucional"; R. D. P. y C.; Tomo 2001 - 1; ed. Rubinzal - Culzoni; Buenos Aires, 2001; págs. 535 a 591; pág. 544.

20 Dictamen de la Comisión № 7 de Integración y Tratados Internacionales; pág. 65.

$21 \quad$ Natale, Alberto; "Comentarios Sobre la Constitución: La Reforma de 1994"; ed. Depalma; Buenos Aires, 1995; 189 págs.; pág. 106.

22 Peña, Julián; "Los Tratados de la Integr..."; art. cit.; pág. 552.
} 
Argentina, de la X Cumbre de Presidentes del Mercosur ${ }^{23}$, a ello debe sumarse el Protocolo de Ushuaia Sobre Compromiso Democrático en el Mercosur, del 24 de junio de 1998, de similar tenor al anteriormente citado, que es ley para la República No 25.133 y que prevé los procedimientos a seguirse en caso de ruptura del orden democrático en alguno de los países y al cual han adherido los países asociados de Chile y Bolivia.

Finalmente, deben los Tratados de Integración respetar los derechos humanos, aclarándose que los Tratados de Derechos Humanos poseen en el art. 75 inc. 22) jerarquía constitucional.

La jerarquía de las normas dictadas en consecuencia de los Tratados de Integración será superior a las leyes, por lo tanto de aplicabilidad directa e inmediata.

\section{Sistema de aprobación y jerarquía constitucional de los Tratados del Mercosur.}

La C.N. prevee dos formas distintas de aprobación de Tratados de Integración, fijándose un procedimiento más simple para los Tratados con países de la Región y un mecanismo más complejo para todo otro tipo de acuerdo con otros países ${ }^{24}$.

Es importante aclarar lo que debe entenderse por país latinoamericano, pensando que deben ser tales los de habla hispana y portuguesa de América del Sur y América Central, quedando fuera los países del Caribe, Estados Unidos y Canadá25. Para estos países debe contarse con la mayoría absoluta de los miembros de cada Cámara, lo que significa la mitad más uno de los diputados y senadores en funciones, y no de los presentes como para

\footnotetext{
$\overline{23}$ Firmado por todos los Estados partes del Mercosur y por su protocolo adicional por los Estados asociados de Chile y Bolivia. En este instrumento se reafirma: "1.- La plena vigencia de las instituciones democráticas es condición esencial para la cooperación en el ámbito del Tratado de Asunción, sus Protocolos y demás actos subsidiarios. 2.- Toda alteración del orden democrático constituye un obstáculo inaceptable para la continuidad del proceso de integración en curso respecto al Estado miembro afectado. 3.- Las Partes consultarán inmediatamente entre sí, en la forma que estimen apropiada, en caso de ruptura o amenaza de ruptura del orden democrático en un Estado miembro. Las Partes procederán igualmente, de forma coordinada, a efectuar consultas con el referido Estado miembro. 4.- En caso de que las consultas previstas en el parágrafo anterior resulten infructuosas, las Partes considerarán la aplicación de las medidas pertinentes. Las medidas podrán abarcar desde la suspensión del derecho de participación en los foros del MERCOSUR hasta la suspensión de los derechos y obligaciones emergentes de las normas del MERCOSUR y de acuerdos celebrados entre cada una de las Partes y el Estado donde haya ocurrido la ruptura del orden democrático. 5.- Las Partes deberán incluir una cláusula de afirmación del compromiso con los principios democráticos en los acuerdos del MERCOSUR con otros países o grupo de paises".

$24 \quad$ Concretamente establece la segunda parte del inc. 24 del art. 75 que:"La aprobación de estos tratados con Estados de Latinoamérica requerirá la mayoría absoluta de la totalidad de los miembros de cada Cámara. En el caso de tratados con otros Estados, el Congreso de la Nación, con la mayoría absoluta de los miembros presentes de cada Cámara, declarara la conveniencia de la aprobación del tratado y solo podrá ser aprobado con el voto de mayoría absoluta de la totalidad de los miembros de cada Cámara, después de ciento veinte días del acto declarativo.

La denuncia de los tratados referidos a este inciso, exigirá la previa aprobación de la mayoría absoluta de la totalidad de los miembros de cada Cámara".

25 Peña, Julián; "Los Tratados de la Integr..."; art. cit.; pág. 558.
} 
la aprobación de las leyes. Fuera de estos Estados, se requerirá para un acuerdo la mayoría absoluta de los miembros de cada Cámara, pero previa declaración de conveniencia de su aprobación por mayoría de los miembros presentes y pasados ciento veinte días de tal acto, lo que implica una doble instancia legislativa.

En cuanto a la jerarquía constitucional de los Tratados del Mercosur, desde ya vamos anticipando que no la poseen. En primer lugar porque no cumplen con los requisitos del inc. 24, debido a que sus órganos con capacidad decisoria son de carácter intergubernamental y no supraestatal. Por otra parte, respecto del Tratado de Asunción, es anterior a la reforma de la Constitución, con lo que las normas valen para el futuro. El Protocolo de OuroPreto de 17 de diciembre de 1994 posee jerarquía supralegal en virtud del art. 75 inc. 22). Como es sabido, establece el marco jurídico institucional del Mercosur, otorgándole personería del Derecho Internacional, al carácter intergubernamental de los órganos, sobretodo en cuanto a que las decisiones deben ser tomadas, conforme al art. 37 del Protocolo por consenso y con la presencia de todos los Estados Partes.

A ello debe sumarse que la internalización de las normas del Mercosur, conforme al art. 42 del Protocolo, si bien tendrán carácter obligatorio, deben ser incorporadas a los ordenamientos jurídicos nacionales mediante los procedimientos previstos por la legislación de cada país.

En definitiva y reiterando lo ya dicho el Mercosur en estos momentos encuadra dentro del art. 75 inc. 22) en cuanto a la jerarquía supralegal de los Tratados, pero no en el analizado art. 75 inc. 24).

\section{Cuestión de competencia entre la nación y las provincias.}

En el aspecto interno, la organización de la República Argentina está dada por el art. 1 de la Constitución Nacional, el cual declara: "La Nación Argentina adopta para su gobierno la forma representativa, republicana federal, según la establece la presente Constitución”. En razón de la organización federal existen competencias que corresponden a la Nación y otras a las Provincias. El principio general es que todo el poder no delegado a la Nación reside en los Estados Provinciales ${ }^{26}$.

\footnotetext{
26 Y así lo declaran los artículos 121 y 122 de la C. N., en su título referente a los gobiernos de provincia: "Art. 121: Las provincias conservan todo el poder no delegado por esta Constitución al Gobierno federal, y el que expresamente se hayan reservado por pactos especiales al tiempo de su incorporación. Art. 122: Se dan sus propias instituciones locales y se rigen por ellas. Eligen sus gobernadores, sus legisladores y demás funcionarios de provincia, sin intervención del Gobierno federal.". Declarando posteriormente el art. 126 toda una serie de competencias que permanecen delegadas a la nación: "Art. 126: Las provincias no ejercen el poder delegado a la Nación. No pueden celebrar tratados parciales de carácter político; ni expedir leyes sobre comercio, o navegación interior o exterior; ni establecer aduanas provinciales; ni acuñar moneda; ni establecer bancos con facultad de emitir billetes, sin autorización del Congreso Federal; ni dictar los Códigos Civil, Comercial, Penal y de Minería, después que el Congreso los haya sancionado; ni dictar especialmente leyes sobre ciudadanía y naturalización, bancarrotas, falsificación de moneda o documentos del Estado; ni establecer derechos de tonelaje; ni armar buques de guerra o levantar ejércitos, salvo el caso de invasión exterior o de un peligro tan inminente que no admita dilación dando luego cuenta al Gobierno federal; ni nombrar o recibir agentes extranjeros."
} 
Se deben distinguir dos cuestiones: una, las potestades legislativas entre el Congreso de la Nación y las distintas Legislaturas Provinciales y otra, las judiciales. Lo primero que nos compete saber es que las normas que van a delimitar la competencia judicial internacional argentina deben ser dictadas por el Congreso de la Nación y por lo tanto van a ser normas nacionales ${ }^{27}$, de naturaleza federal, debiendo tener en cuenta que no existe en la Constitución Nacional una norma explícita que defina esta potestad, pero que es facultad implícita del Congreso de la Nación dictar las normas de competencia judicial internacional ${ }^{28}$. Y esto siempre y pacíficamente ha sido así, desde la misma constitución de la República. Lo segundo, las potestades judiciales. Cada Provincia posee su propia organización judicial y dicta sus propios Códigos Procesales. La Nación también dicta sus propias normas de procedimiento ${ }^{29}$ y conoce en su organización judicial aquellas cuestiones que se denominan "materia federal" y que se derivan de las normas constitucionales que establecen el "Poder Judicial de la Nación" ${ }^{30}$, estas competencias están reguladas entre las "Atribuciones del Poder Judicial" en la Constitución Nacional y las leyes que los reglamentan ${ }^{31}$.

Ahora, en último término, el control de la competencia judicial internacional en la República Argentina es realizado por la C.S.J.N. "cuando la jurisdicción depende de la interpretación de un tratado internacional, o cuando la interpretación de normas internas relativas a dicha jurisdicción puede conducir a una privación concreta de justicia en el orden

$27 \quad$ Uzal, María Elsa; "Algunas Reflexiones Sobre Temas de Derecho Procesal Internacional"; L.L.; Tomo 1998 - E, sec. doctrina; págs. 1075 a 1080; pág. 1077: "Los criterios de atribución de jurisdicción internacional deben ser fijados por leyes nacionales, mientras que los criterios de competencia "especial" deberían seguir siendo resorte de las provincias".

28 Boggiano, Antonio; "Derecho Internacional Privado"; ed. Abeledo - Perrot; Buenos Aires, 1992; Tomo I, pág. 100: "Por su función delimitadora de la soberanía jurisdiccional de los jueces argentinos, aquellas normas de jurisdicción internacional revisten naturaleza federal autónoma, aun cuando se hallen incorporadas a las leyes comunes. El deslinde de la jurisdicción de los jueces argentinos frente a la de los tribunales extranjeros configura, de por si, cuestión federal... Sería irrazonable que las autoridades provinciales dictaran esas normas, por la necesidad esencial de regulación argentina uniforme." Y del mismo autor; "Conflictos de Jurisdicción Internacional Ante la Corte Suprema de Justicia de la Nación - Cuestiones Federales de Jurisdicción Internacional"; E.D.; Tomo 62; págs. 619 a 628, pág. 627 in fine.

$29 \quad$ En este sentido, como la jurisdicción internacional de los tribunales argentinos es federal, ella se rige por las normas que dicta la nación, por la potestad legislativa que posee el Congreso Nacional en la materia, por eso, se regirá por las normas de procedimiento nacionales.

$30 \quad$ El Artículo 108 establece que: "El Poder Judicial de la Nación será ejercido por una Corte Suprema de Justicia, y por los demás tribunales inferiores que el Congreso estableciere en el territorio de la Nación".

$31 \quad$ El art.116 de la C. N. establece: "Corresponde a la Corte Suprema y a los tribunales inferiores de la Nación, el conocimiento y decisión de todas las causas que versen sobre puntos regidos por la Constitución, y por las leyes de la Nación, con la reserva hecha en el inciso 12 del Artículo 75; y por los tratados con las naciones extranjeras; de las causas concernientes a embajadores, ministros públicos y cónsules extranjeros; de las causas de almirantazgo y jurisdicción marítima; de los asuntos en que la Nación sea parte; de las causas que se susciten entre dos o más provincias; entre una provincia y los vecinos de otra; entre los vecinos de diferentes provincias; $y$ entre una provincia o sus vecinos, contra un Estado o ciudadano extranjero." El inciso 12 del artículo 75 al que refiere esta norma establece la atribución del Congreso de la Nación de dictar las normas materiales de derecho. Estableciendo el art. 117 las reglas básicas de distribución interna de competencias en la justicia nacional: "En estos casos la Corte Suprema ejercerá su jurisdicción por apelación según las reglas y excepciones que prescriba el Congreso; pero en todos los asuntos concernientes a embajadores, ministros y cónsules extranjeros, y en los que alguna provincia fuese parte, la ejercerá originaria y exclusivamente". 
internacional, cuestionando directamente, entonces, nuestra garantia constitucional de la defensa en juicio"32. Las normas de competencia judicial internacional argentinas revisten naturaleza federal, sea que su fuente se halle en un Tratado, sea que se encuentren en leyes nacionales comunes ${ }^{33}$. Por otra parte es usual que las normas estén insertas en los cuerpos comunes de leyes sustantivas, como por ejemplo los códigos. Este hecho en nada afecta su naturaleza de norma de competencia judicial internacional ${ }^{34}$.

Esto así fue interpretado por la jurisprudencia de la C.S.J.N., en los casos: "Eberth Clemens B.m.b.H. c/ Buque Pavlo", fallo del 25 de noviembre de 1975, donde se dice: "Que hallándose controvertida en los autos principales la inteligencia de normas que revisten carácter federal, por versar sobre cuestiones de transporte maritimo y de jurisdicción internacional de los tribunales argentinos, existe en la causa cuestión federal bastante para ser considerada en la instancia del art. 14 de la ley 48". Posteriormente esto se vuelve a confirmar en "Maruba S.C.A. empresa de Navegación Marítima c/Itaipu s/Daños y Perjuicios", del 5 de febrero de 1998, donde se establece en el considerando tercero: "Que el recurso extraordinario es formalmente admisible pues se halla en tela de juicio el reconocimiento del privilegio de inmunidad de jurisdicción a una organización internacional intergubernamental, lo cual entraña interpretación de normas federales". Finalmente en "Exportadora Buenos Aires S.A. c/ HolidayInn'sWorldwide Inc." ${ }^{35}$, del 20 de octubre de 1998. En el que además de citarse estos dos antecedentes se dice en el considerando tercero: "Que uno de los agravios que presenta la parte recurrente suscita cuestión federal suficiente, pues comporta la interpretación y aplicación de normas de jurisdicción internacional-que revisten naturaleza federal aun cuando estén insertas en un cuerpo normativo de derecho común -, y la decisión ha sido contraria a la pretensión que el apelante fundó en ellas... "36.

\footnotetext{
$\overline{32}$ Boggiano, Antonio; "Derecho Internacional Priv..."; op. cit.; Tomo I; pág. 150.

33 Esta es la tesis que sostiene Boggiano en el artículo "Conflictos de jurisdicción internacional ante la Corte..."; op. cit.; página 627: "Con independencia de la eventual privación de defensa sustancial, es además razonable que la autoridad jurisdiccional superior del pais decida, revisándolos en cada causa, los límites externos de la soberanía jurisdiccional de la Nación, esto es, los precisos alcances de los principios de interdependencia e independencia jurisdiccionales argentinos, sea interpretando normas internas, sea haciéndolo con normas oriundas de Tratados internacionales".

$34 \quad$ Ramayo, Raúl Alberto; "Nueva Doctrina de la C.S.J.N., y sus Potenciales Consecuencias Institucionales en el Ámbito de las Jurisdicciones Internacional, Nacional y Provincial"; E.D.; Tomo 167; págs. 19 a 31; pág. 25: "La naturaleza federal de las leyes (internas y convencionales) que determinan la jurisdicción ius privatista internacional argentina, conviven jurídicamente en armonía con las leyes sustantivas de derecho común. Ocurren en esta materia, valga la metáfora, algo similar a lo que acontece con una obra pictórica (en nuestro caso la jurisdicción internacional) no se confunde ni traslada su naturaleza a la tela receptora de la pintura del artista (en nuestro caso el derecho común)".

35 L.L.; Tomo 2000-A; págs. 404 a 427.

$36 \quad$ En el mismo sentido puede citarse la jurisprudencia de la C.S.J.N. en el caso: "PacesetterSystems Inc. S.A. s/pedido de quiebra por Pacesetter S.A.", del 9 de junio de 1994, donde en el voto en disidencia del juez Boggiano con relación a la naturaleza federal de las normas de competencia judicial internacional insertas en la ley de quiebras se dice en el considerando noveno: "que si bien el precepto en cuestión está incluido en un cuerpo legal de aquellos sancionados por el Congreso de la Nación de acuerdo con las facultades que le otorga la primera parte del inciso 11 del art. 67 de la Constitución Nacional, el carácter de una ley no impide que parte de ella pueda ser de naturaleza diferente... el art. $2^{\circ}$ inciso $2^{\circ}$ de la ley 19551, por ser norma de jurisdicción internacional, delimitadora de la soberanía de los jueces argentinos, reviste naturaleza federal."
} 
De todo este planteo cabe aclarar que quedan totalmente excluidas las normas que se incorporan a través de Tratados internacionales, ya que es facultad del gobierno federal su conclusión.

\section{El Orden Público Internacional Argentino.}

Analizaremos a continuación el Orden Público Internacional Argentino ${ }^{37}$, institución que posee su origen histórico concreto en el autor alemán Friederich Carl von Savigny, en su "Sistema de Derecho Romano Actual”. Probablemente debido al jurista suizo Charles Brocher del S. XIX, que seguía las premisas de Savigny, se ha buscado la diferenciación entre orden público interno y orden público internacional. Como lo señala Martín Wolff $^{38}$, Savigny distingue a las normas de orden público (aunque recordamos las llamó rigurosamente prohibitivas) o de carácter imperativo, iuscogens de todo sistema, en dos tipos, las primeras son establecidas simplemente en provecho de las personas que son los poseedores de los derechos, tales como la capacidad de actuar. En segundo lugar, las leyes que no se hacen en beneficio de individuos aislados, sino que descansan en motivos morales o en el interés público si se refieren a la política, orden o economía pública.

Brocher propuso a la primera postura de Savigny como leyes de orden público interno y a las segundas como leyes de orden público internacional, deseando indicar con eso que las leyes de la primera categoría son aplicables sólo cuando se aplica el derecho interno del foro mientras que el segundo grupo exige imperativamente la aplicación aun en la esfera del Derecho Internacional Privado del país.

Tal como señala Goldschmidt, el orden público supone dos circunstancias dadas por la diversidad ideológica dentro de la comunidad de aquellos pueblos que aplican mutuamente sus respectivos derechos y el reconocimiento de una obligación jurídica de aplicar derecho extranjero ${ }^{39}$. Fernández Arroyo lo define diciendo que: "Es la obstaculización de los efectos de una decisión extranjera en el foro, basándose en la detección de una contradicción manifiesta entre contenido de la decisión extranjera y los principios de orden público del Estado requerido" ${ }^{\prime 2}$. Dicho autor nos explica que el alcance de la incompatibilidad manifiesta abarca un obstáculo insalvable a un principio jurídico del ordenamiento. Ese obstáculo debe seguir el principio de vinculación suficiente.Debe haber un vínculo esencial entre el

\footnotetext{
$\overline{37} \quad$ Si desea verse un interesante desarrollo de la evolución histórica puede consultarse: Mendiolea, Alfredo Andere; "El Orden Público Nacional y el Orden Público Internacional en México, Una Consideración y Necesidad Evolutiva Para el Derecho Internacional Privado"; R.M.D.I.Pr. y C.; No 14, octubre de 2003; México, 2003; págs. 95 a 115.

$38 \quad$ Wolf, Martín; "Derecho Internacional Privado"; ed. Bosch; Barcelona 1958; págs. 162 y ss.

39 Goldschmidt, Werner; "Derecho Internacional Priv..."; op. cit. pág. 147.

$40 \quad$ Fernández Arroyo, Diego (coordinador); "Derecho Internacional Privado de los Estados..."; op. cit.; pág.
} 
Estado sentenciante y el Estado requerido para que se genere el rechazo por ir en contra de sus intereses fundamentales ${ }^{41}$. Este término de "manifiestamente contraria" se deriva del art 5 de la CIDIP II de Montevideo de 1979 sobre Normas Generales de Derecho Internacional Privado de la cual la República Argentina es parte. En una brillante sentencia el juez Fermé ${ }^{42}$, citando a Margarita Argúas, explica que el término "manifiestamente" importa una incompatibilidad que debe saltar a los ojos del juez ${ }^{43}$.

El orden público, tal como explica Goldschmidt, desde su antigua concepción, puede ser concebido como un conjunto de disposiciones, o como un conjunto de principios $^{44}$. El concebirlo como conjunto de disposiciones implica su aplicación, a priori, con total prescindencia del derecho extranjero, porque las disposiciones de orden público internacional pasan a ser sustitutivas de las extranjeras. En cambio si se concibe como un conjunto de principios, pasan a ser limitativas de las normas extranjeras y por lo tanto a posteriori. Por ello el orden público internacional es el aspecto negativo de la consecuencia jurídica en la estructura de la norma ${ }^{45}$.

Normativamente al orden público lo vemos tratado en el art. 14 del Cód. Civ. cuando dice: "Las leyes extranjeras no serán aplicables: 1ro.) Cuando su aplicación se oponga al derecho público o criminal de la República, a la religión del Estado, a la tolerancia de cultos, o a la moral y buenas costumbres; 2do.) Cuando su aplicación fuere incompatible con el espiritu de la legislación de este Código; 3ro.) Cuando fueren de mero privilegio..." . El inc. 2, al destacar el espíritu de las leyes, estatuye al orden público como conjunto de principios. Junto a esta cláusula general de orden público, a lo largo del ordenamiento encontramos toda una serie de cláusulas particulares, como normas no dispositivas y que obstaculizan la aplicación del derecho extranjero, tal como podrían citarse los art. 1206 a 1208 del Cód. Civ.. Así lo

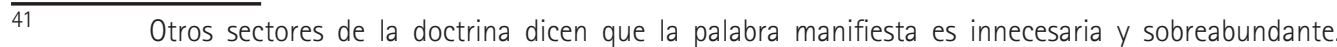
Marzorati, Osvaldo; "Derecho de los Neg..."; op. cit. pág. 397.

42 Caso "G., E.I. i otro C. S.R. y otros"; dado por la CNCiv., Sala I, el 24 de febrero de 2000, L.L. Tomo 2000D; págs. 236 y ss.

$43 \quad$ El orden público así expresado lo encontramos en ordenamientos legislativos como la Ley Suiza de Derecho Internacional Privado, al decir en el art. 27: "manifiestamente incompatible con el orden público suizo", de alli que autores como Bucher, Andreas; "Droit Inter..."; op. cit.; pág. 212, lo denominen como "orden público atenuado".

$44 \quad$ Goldschmidt, Werner; "De Nuevo: el art. 67 bis de la Ley 2393 y el Orden Público Internacional"; comentario al fallo "B. G. y otro."; CNCiv. Sala C; 14 de diciembre de 1982; L.L.; Tomo 1983-C; págs. 121 y ss..

$45 \quad$ En cuanto a la explicación del orden público como conjunto de principios puede verse: Goldschmidt, Werner; "El Orden Público Internacional (O.P.I.) en el Derecho Internacional Privado (DIPr.)"; E.D.; Tomo 109; págs. 889 a 894; pág. 891: "Prescindiendo de las normas rígidas expresas, el O.P.I. no es nunca cualidad de normas sino lo es de los principios. No es de O.P.I. por ejemplo el cumplimiento de 18, 19 o 20 años como principio de la mayoría de edad sino el principio de que debe gozar de la mayoría de edad quien disfruta de la madurez intelectual y moral. No es de O.P.I. la regla que los descendientes hereden obligatoriamente cuatro quintas partes o dos tercios de los ascendientes sino que deben heredar una parte considerable del patrimonio de los ascendientes. Por consiguiente, el O.P.I. no se opone a una disposición extranjera que discrepe de una disposición patria sino que se rebela sólo contra una disposición extranjera que estribe en un principio extranjero incompatible con nuestros principios. La mayoría de edad extranjera de 18 años no infringe nuestro O.P.I. aunque la nuestra comienza tres años más tarde. En cambio si conculcaría nuestro O.P.I. una mayoría de edad que empezaría ya con 12 o con 40 años..." 
ha determinado la jurisprudencia en el caso: "Balda Werke S.C. en 498 Bunde Westfalia c. Francisco Freund S.A." ${ }^{46}$, que trataba de un reclamo sobre el pago de mercaderías que habían sido sub facturadas a los efectos de evadir derecho aduaneros.

Tenemos entonces un orden público interno que comprende el conjunto de aquellas disposiciones derogables por la autonomía de las partes, pero sí aplicables en virtud del derecho extranjero aplicables por el Derecho Internacional Privado y un Orden Público Internacional, como principios subyacentes a nuestras disposiciones, que estimamos inalienables, inclusive con miras al derecho extranjero aplicable por el Derecho Internacional Privado.

Ahora, si debemos hacer una clasificación de las doctrinas aplicadas en la materia ${ }^{47}$, diremos que están aquellos que lo conciben como un remedio excepcional a la aplicación de derecho extranjero, y aquellos que lo ven de manera contraria, o sea que la excepción es la aplicación del derecho extranjero. A su vez están los criterios monistas de un solo orden público y los dualistas con el orden público interno e internacional.

Podemos ver también la distinción entre un orden público sustantivo y otro orden público adjetivo $^{48}$.

Este orden público que denominamos adjetivo, también puede ser denominado procesal, donde se pondrá énfasis en las garantías consagradas y ya desarrolladas más arriba, siendo esencial el haber accedido a la tutela judicial y a una garantía judicial efectiva. Dentro de este tema ingresa la imparcialidad del tribunal, la suficiente fundamentación de la decisión, el correcto emplazamiento, etc. Algunos autores hablan de un test de aplicación del orden público procesal diciendo que es siempre un test de indefensión material y no de regularidad legal explicando que: "no se controla ni el grado de ajuste o convergencia del derecho procesal extranjero con el derecho del foro, ni la conformidad o corrección del proceso a la luz de su propio derecho procesal aplicable, el del Estado de origen. Además en este test la conducta del demandado en el extranjero es directamente relevante, si pudiendo no utilizó los

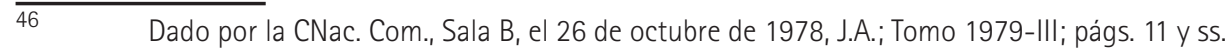

$47 \quad$ Para la génesis histórica y la exposición de las diferentes doctrinas puede verse: Ruchelli, Humberto Fernando - Ferrer, Horacio Carlos; "El Orden Público", ed. Abeledo-Perrot; Buenos Aires, 1991; 82 págs.

$48 \quad$ bíd..; pág. 77. Otros autores hablan de una triple clasificación, así: Remiro Brotons, Antonio; "Ejecución de Sentencias..."; op. cit.; pág. 226 y 227: "...el orden público asume una triple connotación: sustantiva, conflictual y procesal...Impedirá la aplicación de la ley extranjera requerida por la regla de conflicto en la medida en que según el juzgador, su contenido sea incompatible con los principios inspiradores del ordenamiento del foro. He aqui el orden público sustantivo...El orden público procesal protegería esos mismos intereses y también en su caso los de las partes desde el punto de vista del juez que dictó la sentencia, del respeto de los derechos de defensa, de los medios de prueba, etc... Por último el orden público conflictual daría paso, con mayor o menor extensión al control de la competencia legislativa." Este autor explica que el control de la competencia legislativa es la atribución del juez del exequátur de la facultad - que es deber - de verificar si el juez extranjero que dictó la sentencia sometida a trámite aplicó o no, para resolver el litigio, la ley designada por el sistema conflictual del foro. Si la constatación es negativa el exequátur debería ser denegado. Esta postura nos parece desacertada, dado que en definitiva implica un control del fondo que excede el análisis del orden público.
} 
medios de recurso disponibles en el Estado de origen (siempre que sean potencialmente efectivos) estará precluido en la fase de reconocimiento"’39.

Cierto sector de la doctrina nos habla de un orden público a la luz de los principios constitucionales, y de la dimensión Convencional, tal como los principios consagrados en la Convención Americana de Derechos Humanos, la Declaración Universal de los Derechos Humanos, el Pacto Sobre Derechos Políticos y Civiles, y todo el plexo de Constitucionalidad en materia de derechos humanos incorporados en la reforma de $1994^{50}$. Este criterio de "orden público constitucional" es el seguido por el Tribunal Supremo español, en cuanto sólo será procedente la excepción cuando el árbitro o tribunal extranjero haya pronunciado su resolución judicial en clara infracción a los derechos fundamentales reconocidos en la constitución" ${ }^{51}$. También el T.J.C.E. en el caso "Krombach" 52 determinó que: "el reconocimiento o la ejecución de la resolución dictada en otro Estado contratante choque de manera inaceptable con el ordenamiento juridico del Estado requerido, por menoscabar un principio fundamental. Para respetar la prohibición de revisión en cuanto al fondo de la resolución extranjera, el menoscabo debería constituir una violación manifiesta de una norma jurídica considerada esencial en el ordenamiento jurídico del Estado requerido de un derecho reconocido como fundamental en ese ordenamiento".

Ahora, en cuanto el orden público constitucional sobre el, que en principio estamos de acuerdo, cabe la aclaración que nos hace Ciuro Caldani en cuanto al contenido al decir: “... si se tiene en cuenta que la constitución formal abarca habitualmente formaciones de alcance universal (quizás el derecho a la defensa en juicio) internacional de reserva (o sea excluyente: libertad de esclavos al pisar suelo argentino) y nacional (libertad de navegación) y que una misma solución puede pertenecer a en distintos niveles a diferentes clases (la igualdad básica entre los esposos es de alcance nacional pero no la sumisión de la mujer al capricho del marido es internacional excluyente o quizás universal), se advierte que una normatividad constitucional no integra necesariamente el orden público. Por otro lado si se observa que no todas las normatividades universales o internacionales excluyentes están ni pueden estar en la constitución

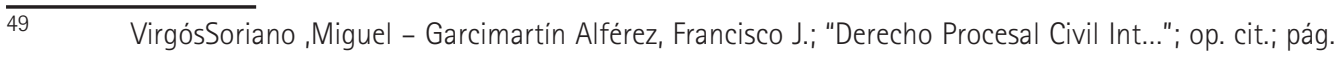
477.

50 Morello, AugustoMario - Sosa, Gualberto Lucas - Berizonce, Roberto Omar; "Códigos Procesales en lo Civil y Comercial de la Prov..."; op. cit. pág. 197.

$51 \quad$ Lorca Navarrete, Antonio Ma; "La Cláusula de Orden Público en la Homologación de Laudos Arbitrales y Sentencias Extranjeras en España, Según la Doctrina del Tribunal Constitucional Español"; L.L.; Tomo 1987 - D; sec - doctrina; págs. 800 a 804.

52 Sentencia T.J.C.E. de 28 de marzo de 2000, Asunto C-7/98. Pueden verse en detalle los supuestos fácticos del caso y un interesante comentario de Santiago Gardeñes, Miguel; R.E.D.I.; Vol. LII. - 2000; Núm. 1; ene - jun; pág. 192. Básicamente diremos que el sr. Krombach, de nacionalidad y domicilio alemán, fue condenado por una jurisdicción penal francesa por un delito de homicidio por imprudencia. También fue condenado a pagar una elevada suma por la responsabilidad civil derivada del delito, lo que motivó que el padre de la víctima pidiese el reconocimiento de la sentencia francesa en Alemania, la cual había sido dictada en rebeldía. Los tribunales alemanes acceden al pedido lo que motivó la apelación del Sr. Krombach.
} 
formal se nota que no todo el orden público está contenido en la normatividad constitucional’\$3. Por ello, cierto sector de la doctrina ${ }^{54}$ habla de que algunos principios son de orden público verdaderamente internacional o de iuscogens, a raíz de que los derechos humanos se han internacionalizado, dejando de ser una cuestión de derecho interno, porque más allá de la Constitución están los Tratados, las declaraciones y la jurisprudencia internacional.

\section{El Orden Público Internacional en el Mercosur.}

También cabe mencionar que hay autores que hablan de un orden público regional, en relación a todas las fuentes derivadas del derecho del Mercosur ${ }^{55}$, concibiéndose el Derecho Internacional Privado Institucional como una nueva fuente de derecho con sus propias normas. Lo cierto también es que los Protocolos contienen reglas que impiden su aplicación, cuando resultan lesivas a las normas y principios locales, pero ello no hace concretamente al orden público subregional, sino que éstos se basan en los principios de la integración subregional. De todos modos, una gran dificultad para definir este concepto es la carencia de un órgano judicial regional que, tal como hace el T.J.C.E lo defina, el Mercosur carece de Derecho Comunitario, por lo que no puede ser todavía definido como un verdadero esquema de integración regional; a pesar de constituir un nuevo ámbito de producción de normas jurídicas, por ello no puede hablarse con total presión de un orden público regional, aunque sí de principios que lo prefiguran.

\section{Conclusiones.}

La República Argentina se enrola desde su normativa y jurisprudencia en un monismo acentuado, que es la tendencia mundial ante la globalización y la internacionalización, dándose como se dijo primacía al derecho internacional por sobre el derecho interno.

A su vez, tenemos los Tratados incorporados constitucionalmente del art. 75 inc. 22 referentes a Derechos Humanos, que están conforme al texto constitucional en el mismo plano de la C.N.

En cuanto a los Tratados de integración tenemos el inc. 24 del art. 75 de la C.N., en que se entiende que el constituyente ha apoyado los procesos de integración, asignando a

\footnotetext{
$53 \quad$ CiuroCaldani, Miguel Ángel; "Meditaciones Trialistas Sobre el Orden Público"; J.A.; Tomo 1977 - II; págs. 711 a 718; pág. 715.

$54 \quad$ Najurieta, María Susana; "Orden Público Internacional y Derechos Fundamentales del Niño"; L.L.; Tomo 1997 - B; págs. 1436 y ss.

55 Dreyzin de Klor, Adriana; "El Orden Público Subregional"; R.D.P. y C.; No 12; ed. Rubinzal - Culzoni; Santa Fe 1996; págs. 507 a 538.
} 
dichos Tratados jerarquía superior a las leyes y habilitando la modificación de competencias de los poderes del Estado Argentino a favor de un ente regional.

En cuanto a la jerarquía constitucional de los Tratados del Mercosur no la poseen, porque no cumplen con los requisitos del inc. 24, debido a que sus órganos con capacidad decisoria son de carácter intergubernamental y no supraestatal.

El contenido del Orden Público Internacional Argentino está formado, en esencia, por los principios base del ordenamiento jurídico concebido de forma sistémica y cambiante. Se considera que no puede hacerse una reducción a la C.N. y los Tratados de Derechos Humanos, sino un subsunción de ellos, donde puede ser más amplio o reducido.

Asumimos que forma parte de tal las Sentencias de la CorteIDH desde el Control de Convencionalidad por una parte, y desde el acervo que en materia de Derechos Humanos se considera como parte del iusCogens

Concebimos al Sistema Interamericano de Derechos Humanos como parte del acervo del Orden Público Internacional del Mercosur.

\section{Milton C. Feuillade}

Investigador del CONICET (Consejo Nacional de Investigaciones Científicos y Técnicas de la República Argentina - Ministerio de Ciencia, Tecnología e Innovación Productiva) miltonfeuillade@hotmail.com 